\title{
EFFECTS OF IMPLEMENTING CLINICAL PATHWAY ON PAIN AND ANXIETY FOR PATIENTS UNDERGOING CARDIAC SURGERY ${ }^{1}$ Rasha Hassan Abass, ${ }^{2}$ Hanan Mohamed Soliman ${ }^{3}$ Amany Mohamed Shebl, \\ 1Assistance Lecturer of Medical Surgical Nursing, Faculty of Nursing, Mansoura University 2Associated Professor of Medical Surgical Nursing, Faculty of Nursing, Mansoura University 3 Professor of Medical Surgical Nursing, Faculty of Nursing, Mansoura University E-mail of corresponding author: rasha_za2000@yahoo.com
}

\begin{abstract}
Background :Vulvular heart replacement surgery is an increasingly important in cardiac valve disease management .VHRS tends to be suitable for clinical pathway development because high volume, high cost of the surgery and predictable course of events that occur during hospitalization .The aim of this study was to determine the effects of implementing clinical pathway on pain and anxiety for patients undergoing cardiac surgery . Subject and methods, this is a randomized controlled design was utilized. This study was carried out in cardiothoracic surgery unit at the Mansoura University Hospital . A Purposeful sample of 50 adult patients of both sexes scheduled for vulvular heart replacement surgery was included in the study ( 25 clinical path group and 25 control group ). Two tools used for data collection pain scale tool and State trait anxiety inventory. The clinical pathway for cardiac surgery patients conducted in four phases : Phase one : patients assessment, Phase two :cardiac valve surgery clinical pathway establishment and jury. Phase three: implementation and tracking variances . Phase four :Evaluation .The main results of study demonstrated no statistical significant differences in basic data on admission, ,the CP group had significantly lower level of anxiety and pain than the control group before and after surgery . All of the patients in CP group had no variance from VHRS pathway which prove the preset hypothesis of the study .
\end{abstract}

Key words: Clinical pathways, Cardiac valve Surgery, Anxiety „Pain

\section{Introduction:}

Vulvular heart diseases (VHD) are the most common type of open heart surgery and constitute the most important health problem affecting people of productive age. Worldwide in 2013, one quarter of all deaths $(616,000)$ was from vulvular heart diseases. In 2014, $(777,000)$ people died from vulvular heart replacement surgery. In USA approximately every 25 seconds, an American will have a vulvular event, and approximately every minute, someone will die (1)

In the developing world, vulvular heart diseases tend to affect people at a younger age and thus could negatively affect the workface and economic productivity (2). In Egypt, according to latest World Health Organization (WHO) data published in April 2014 vulvular heart disease deaths in Egypt reached 78,998 or $21.75 \%$ of total deaths. The Death Rate is 174.98 per 100,000 of population ranks Egypt 34 in the world (2).

One of the health care systems that provide quality care with decreased costs is the clinical pathway system, also known as care pathways, care maps, and clinical pathways (3) Clinical pathways have been standard in health care as, multidisciplinary care plans that outline the steps and timing of actions necessary 
for achieving expected patient outcomes and organizational goals regarding quality of care, patient satisfaction, costs and efficiency. Many pathways are incorporated into the medical record or are computerized, for a permanent part of the clinical pathway record (4).

One of the high volume and expensive procedure where clinical pathways were first introduced is open heart surgery. Clinical pathway have been designed for both $\mathrm{CABG}$ and vulvular surgeries since the late 80 s and early $1990 \mathrm{~s}$,in the United state , United Kingdom and other parts of the world . An estimated 6.2 million inpatient cardiovascular operations and procedures are performed in the United State each year, accounting for 82000 valve procedures and 516000 coronary artery bypass graft (CBAG) surgeries. On the other hand about 2716 open heart procedures done in the National Heart Institute (NHI) (5)

Clinical pathways (CPs) benefits all parties involved; patients, professionals and the authorities' .patients are better informed, meaning that their perception of quality improves. Clinical processes are simplified for professionals, meaning that they are able to obtain better results and protected from legal action. And lastly, they are positive for the authorities' more efficient processes mean that fewer complaints are received and they encourage better coordination between the departments and with primary care (6) Patient's recovery from cardiac surgery usually a routine and predictable course that when coupled with managed care incentives make it amenable to the development of rapid recovery programs .The cost of hospital care have been directly associated with length of stay, and it is apparent that up to twenty five percent of costs associated with open heart surgery are incurred in prolonged length of stay in cardiothoracic unit has been associated with related complications e.g. ,reoperation , and exploration for bleeding (7). Consequently many health care settings develop and implement clinical pathways for cardiac surgery patients, in order to reduce cost of caring ,decrease occurrence of complications, shorten length of hospital stay and streamline the patient care which will lead to lower direct and indirect cost without an increase in mortality and readmission rate .Therefore, implementing this study is one way to determine the outcomes of implementing clinical pathway for patients undergoing vulvular heart replacement surgery.

\section{Significance of the study}

Despite the fact that Clinical pathways (CPs) were widely used to care for patients throughout the 80s and 90s and several countries worldwide adopted their use , clinical pathways were not used to care for patients' neither in public nor private hospitals until year 2004 when they were introduce in a private hospital at Cairo namely Dar Al-Fouad Hospital. Data generated from this study can lead to improvement in patient's care and satisfactions It also ensures that consistency and quality of care, and decreases hospital stay as well as cost, For these reasons, there was an urgent need to conduct this study in cardiothoracic surgery unit in mansoura university hospital . It is also hoped that this effort will generate attention and motivation for further studies into this topic.

\section{Aim of the study}

The aim of this study was to determine the effects of implementing clinical pathway on pain and anxiety for patients undergoing cardiac surgery

\section{Hypotheses of the study}

H 1: Patients undergoing cardiac surgery who exposed to clinical pathway will have pain level less than those groups who are 
receiving routine hospital care (control group).

H 2: Patients undergoing cardiac surgery who exposed to clinical pathway will exhibit decreased in anxiety level than those groups who are receiving routine hospital care (control group).

\section{Subjects and methods: Research Design:}

The current research design was a randomized controlled trial (RCT), this category of design is a way of doing impact evaluation in which the population receiving the program or policy intervention is chosen at random from the eligible population, and a control group is also chosen at random from the same eligible population. It tests the extent to which specific, planned impacts are being achieved

(Gribbons, Barry, \&

Herman, 2004).

Sample

A Purposeful sample of 50 adult patients of both sexes scheduled for vulvular heart replacement surgery

\section{Inclusion criteria for selection of the} sample .

- All adult aged ranges from +18-60 years old of both sexes undergoing vulvular heart replacement surgery

- Able and willing to communicate and cooperate

- Patients with a Euro score of (less than 10 Euro score) ( 8).

\section{Exclusion criteria.}

- Emergency operations

- The patients with left ventricular ejection fraction of less than $40 \%$., High -risk

- patients with Euro score $>10$ will be excluded from the study.

\section{Subject Drop out}

Subject randomly collected then allocated randomly to clinical pathway group ( 25 patients ) and control group (25 patients) by the end of data collection one patients drops out (died from control group). So, replication of one case of control group patient was carried out in order to match the control group to be as similar as the clinical pathway group so that exclude external variable confusion.

\section{Setting}

This study was conducted at the Cardiothoracic Surgery Unit at the Mansoura University Hospital located in delta region vulvular heart replacement surgeries were performed on a regular basis, daily at Cardiothoracic Surgery Unit in Mansoura University Hospital with an average number of two cases weekly .

\section{Tools for Data Collection:}

- Tool I: Pain Assessment Scale (postoperative).

- Tool II: - State -Trait Anxiety Inventory (preoperative and postoperative )

\section{Pilot study:}

A pilot study was conducted on 10 patients who attended the cardiothoracic unit for vulvular heart replacement surgery . This aimed to ensure clarity, objectivity, relevance, and feasibility as well as to identify any problems associated with administration of the questionnaires and to measure the time needed for data collection with each subject. Modifications were done accordingly. Subjects who shared in the pilot study were excluded from the study sample.

\section{Procedures:}

\section{Patients assessment .}

Patients in both groups clinical pathway and control group were assessed after hospital admission

Since cardiac surgery were performed at regular basis daily at cardiothoracic surgery unit in Mansoura University 
Hospital , with average number of 2 patients each week the researcher observed the patient in the three phases ;preoperative and immediate postoperative in the ward. Then the patient assessed at the beginning of each shift per day till hospital discharge.

- Pain assessment for pain site , intensity, duration, sedation in addition to pain distress assessment using numerical scale was performed at beginning of each shift till hospital discharge .

\section{Phase two.}

- A steering committee was formulated consisting of head nurse of cardiothoracic surgery unit, assistant head nurse, the anesthesiologist, cardiothoracic surgeon, professor of cardiothoracic care nursing , physiotherapist, dietitian, social worker and the researcher to help in establishing the pathway. Then the pathway was established after assessment of current practice through study of hospital routine as baseline for Clinical Pathway Development The researcher observed nurses' performance related to pre and post operative care in cardiothoracic surgery unit before establishing vulvular heart replacement surgery and reviewing related literature .

- The established pathway was examined by nine experts in field of care and education to test for content validity.

- Establishing pathway took approximately seven months

\section{Phase three.}

Educational training sessions were provided to care providers about the purpose and process of implementing pathway for one month after collecting the data of control group.
The established pathway was implemented on the CPG by trained care providers from patient admission till discharge under supervision of researcher .

- Multidisciplinary team implemented the pathway under supervision of researcher and followed patient progress variances' for all studied subjects from admission till discharge

- Variances affecting the adherence to developed pathway were monitored, analyzed, receded, and an action plan was developed to overcome them

- Six patients refused to participate in the study were excluded from my study .

- Implementing pathway took approximately six months .

Data collection of clinical pathway group including three stages of care .

- Pain assessment was done immediately after surgery and hourly in the first day of surgery (Pain Assessment Scale )

Deep breathing exercise was taught to the pain pre vulvular heart replacement surgery in order to decrease pain (Salama, 2013).See (Appendix III)

- Patient position

- Patient's position was changed on specific schedule (Chair et al., 2003)

- Immediate after the patient transfer from recovery room to the unit on supine position

- One hour after the patient transfer from recovery room to the unit on supine with head elevated $15^{\circ}$

- After two hours the patient sleep on lateral position

- After three hours the patient sleep on supine position with head elevated $30^{\circ}$

- Ambulation

Ambulation was initiated gradually in the first day after removal of all connected tubes. It starts with foot 
exercise then sitting on chair and allowing out of bed for half an hour.

Assessed the patients anxiety level before and after surgery (State - Trait Anxiety Inventory)

Variance tracking: patient progress variance was followed from admission till discharge using

Finally after finishing the data collection the control group was interviewed and instructed about all items of care for vulvular heart replacement surgery as well as a Colored Arabic booklet was distributed to those patients or family members to be a guide at home and give telephone number of researcher for any problems

Phase four.

This phase consists of comparing outcomes for both groups according the following.

- Pain intensity.

- Anxiety level.

Human rights and ethical
considerations.
Official approval from ethical

Official approval from ethical committee of faculty of nursing and approval from administrative authority from director of cardiothoracic surgery unit was taken then verbal consent was obtained from each participating patient prior to his/her inclusion into the study after clarification of the nature and aims of the study. The investigator emphasized that participation is absolutely voluntary and confidential. Anonymity, privacy, rights and each participant had the right to withdraw from the study at any time without justification .

- Data was collected, computed and statistically analyzed using SPSS (Statistical Package of Social Sciences) software program version 16.

- The 0.05 level was used as cut off value for statistical significance and the following statistical measures are used : Cronbach's's Alpha reliability test: it was used to measure the reliability of the developed tools. Its maximum value is $(\mathrm{a}=1.0)$ and the minimum accepted value is $(a=0.7)$; below this level the tool would be unreliable.

- Chi square test used to test the association between qualitative variables.

- Likelihood Ratio Chi-square and Fisher exact test were used for tables with cell or more with an expected frequency less than 5

- $\mathrm{T}$ - test it used to test the association between two quantitative variables or to detect difference between two or more proportion

- $5 \%$ level of significant was chosen where $\quad \mathrm{P} \leq 0.05$ was considered significant and $\mathrm{P}>0.05$ was considered as non significant.

- After finishing of data collection the statistical test revealed significant differences between the control and clinical pathway group in relation to basic data on admission

\section{Results}

Table (1)Distribution of the clinical path group and control group regarding their socio demographic characteristics. $\mathbf{N}=\mathbf{5 0}$

This table indicate that :

There was, no differences significant between $\mathrm{CP}$ group and control groups as regard socio demographic characteristics. The groups are matched regard to age, gender, and the level of education, marital status, and occupation. Regarding the age, the table revealed that, $56.0 \%$ and $52.0 \%$ of both CPG and control group were in age between 51-60years and mean age 53.88 years and 52.2 years and the differences was not statistically significant $(\mathrm{T}=0.608$, $\mathrm{P}=0.546)$.In relation to sex half of the clinical path group were males $(52.0 \%)$ 
Rasha Hassan Abass, et. al.

\begin{tabular}{|c|c|}
\hline $\begin{array}{l}\text { and female in CP group \&CP nearly half } \\
(48 \%) \text {. The differences was not } \\
\text { statistically significant }(\mathrm{X} 2=0.325 \text {, } \\
\mathrm{P}=0.569) \\
\text { Regarding marital status the majority } \\
\text { of patient in the clinical path group and }\end{array}$ & $\begin{array}{l}\text { education certificate compared to }(44.0 \%) \\
\text { of control group patients and the } \\
\text { differences was not statistically significant } \\
\text { (FET=1.066, } \mathrm{P}=0.805) \text { In addition, } \\
\text { occupation about half of the both group } \\
\text { patients were occupying a professional } \\
\text { work the CP group }(52.0 \%) \text { and control } \\
\text { group }(48.0 \%) \text { Differences was } \\
\text { statistically significant }(\mathrm{X} 2=4.019 \text {, } \\
\mathrm{P}=0.123) \text {. }\end{array}$ \\
\hline
\end{tabular}
group patients were hold university

Table (1):Distribution of the clinic path group and control group regarding their socio demographic characteristics' $=50$

\begin{tabular}{|c|c|c|c|c|c|c|}
\hline \multirow{3}{*}{$\begin{array}{c}\begin{array}{c}\text { Socio demographic } \\
\text { Data }\end{array} \\
\text { Age group }\end{array}$} & \multicolumn{4}{|c|}{ Groups } & \multirow{2}{*}{$\mathbf{X}^{2}$} & \multirow{2}{*}{$\mathbf{P}$} \\
\hline & \multicolumn{2}{|c|}{$\begin{array}{l}\text { Clinical path group } \\
\qquad N=25\end{array}$} & \multicolumn{2}{|c|}{$\begin{array}{c}\text { Control group } \\
\mathrm{N}=25\end{array}$} & & \\
\hline & $\mathbf{N}$ & $\%$ & $\mathbf{N}$ & $\%$ & \multirow{5}{*}{$\begin{array}{c}0.212 \\
\mathrm{~T}=0.60 \\
8\end{array}$} & \multirow{5}{*}{$\begin{array}{l}0.497 \\
0.546\end{array}$} \\
\hline $20-$ & 3 & 12.0 & 3 & 12.0 & & \\
\hline 35- & 8 & 32.0 & 9 & 36.0 & & \\
\hline 51- 60 & 14 & 56.0 & 13 & 52.0 & & \\
\hline Mean \pm SD & \multicolumn{2}{|c|}{$53.88 \pm 9.457$} & \multicolumn{2}{|c|}{$52.2 \pm 10.079$} & & \\
\hline \multicolumn{5}{|l|}{ Gender } & \multirow{3}{*}{0.325} & \multirow{3}{*}{0.569} \\
\hline Male & 13 & 52.0 & 13 & 52.0 & & \\
\hline Female & 12 & $48.0 \%$ & 12 & $48.0 \%$ & & \\
\hline \multicolumn{5}{|l|}{ Level of education } & \multirow{5}{*}{1.066} & \multirow{5}{*}{0.805} \\
\hline Read and write & 4 & 16.0 & 3 & 12.0 & & \\
\hline Basic education & 5 & 20.0 & 3 & 12.0 & & \\
\hline $\begin{array}{l}\text { Secondary } \\
\text { education }\end{array}$ & 6 & 24.0 & 8 & 32.0 & & \\
\hline $\begin{array}{l}\text { University } \\
\text { education }\end{array}$ & 10 & 40.0 & 11 & 44.0 & & \\
\hline \multicolumn{5}{|l|}{ Marital status } & \multirow{3}{*}{4.100} & \multirow{3}{*}{0.291} \\
\hline Single & 2 & 8.0 & 6 & 24.0 & & \\
\hline Married & 23 & 92.0 & 19 & 76.0 & & \\
\hline \multicolumn{5}{|l|}{ Occupation } & \multirow{4}{*}{4.019} & \multirow{4}{*}{0.126} \\
\hline Not working & 6 & 24.0 & 11 & 44.0 & & \\
\hline Manual working & 6 & 24.0 & 2 & 8.0 & & \\
\hline $\begin{array}{l}\text { Professional } \\
\text { working }\end{array}$ & 13 & 52.0 & 12 & 48.0 & & \\
\hline \multicolumn{5}{|l|}{ Living status } & \multirow{3}{*}{4.100} & \multirow{3}{*}{0.291} \\
\hline Alone & 2 & 8.0 & 6 & 24.0 & & \\
\hline With other & 23 & 92.0 & 19 & 76.0 & & \\
\hline
\end{tabular}

FET $=$ Fisher's Test

Statistical Significance $(\mathrm{P} \leq 0.05)^{*}$ 
Table (2) Distribution of clinical path group and control group patients regarding pain , anxiety and satisfaction $\mathbf{N}=\mathbf{5 0}$

This table reveals that:

The clinical path group experienced moderate pain $60 \%$ and $0 \%$ severe pain compared to $76.7 \%$ and $23.3 \%$ respectively for control group .A statistical significant differences was found between two groups in relation to pain level $(\mathrm{P}=0.000)$.

It can be also be noted that $76.7 \%$ of clinical path group experienced mild anxiety and $\quad 86.7 \%$ of control group experienced moderate anxiety, where as none of the two groups experienced severe anxiety level $(\mathrm{P}=0.000)$.

Table (2): Distribution of clinical path group and control group patients regarding pain , anxiety and satisfaction $\mathrm{N}=50$

\begin{tabular}{|c|c|c|c|c|}
\hline \multirow{3}{*}{ Pain level } & \multicolumn{4}{|c|}{ Groups } \\
\hline & \multicolumn{2}{|c|}{$\begin{array}{c}\text { Clinical path group } \\
\qquad \mathrm{N}=25\end{array}$} & \multicolumn{2}{|c|}{$\begin{array}{c}\text { Control group } \\
\mathrm{N}=25\end{array}$} \\
\hline & $\mathbf{N}$ & $\%$ & $\mathbf{N}$ & $\%$ \\
\hline Mild (1-3 score) & 12 & 40.0 & 0 & 0.0 \\
\hline Moderate (4-6) score & 18 & 60.0 & 23 & 76.7 \\
\hline Severe (7-9) score & 0 & 0.0 & 7 & 23.3 \\
\hline Worst (10) score & 0 & 0.0 & 0 & 0.0 \\
\hline \multirow[t]{2}{*}{ Anxiety } & \multicolumn{2}{|c|}{$\begin{array}{c}\text { Clinical path group } \\
\qquad \mathrm{N}=25\end{array}$} & \multicolumn{2}{|c|}{$\begin{array}{c}\text { Control group } \\
\mathrm{N}=25\end{array}$} \\
\hline & $\mathbf{N}$ & $\%$ & $\mathbf{N}$ & $\%$ \\
\hline Mild 20-39 points & 23 & 76.7 & 4 & 13.3 \\
\hline Moderate $40-59$ points & 7 & 23.3 & 26 & 86.7 \\
\hline Severe $60-80$ points & 0 & 0.0 & 0 & 0.0 \\
\hline
\end{tabular}

Statistical significance $(\mathrm{P} \leq 0.05)$

\section{Discussion:}

This study was implemented in an attempt to determine the outcomes of implementing clinical pathway on pain and anxiety for patient undergoing cardiac surgery Furthermore, World Health Organization (2) reported that; vulvular diseases touch the lives of millions of patients and their Families, together with those who provide and plan care, and those responsible for Planning and funding care especially in developing countries Egypt. Indeed, the WHO estimates that $73 \%$ of the vulvular heart diseases occurs in developing countries (9). Although many patients with vulvular heart diseases can be successfully managed with medications, there are many situations where it is necessary to restore blood flow to the heart muscle and maintain cardiac functions more efficiently by either cardiac valve replacement or by repair (10)

Therefore; the main aim of this study was to determine the outcomes of implementing clinical pathway on pain and anxiety for patient undergoing cardiac surgery. Where the key outcomes was to decrease pain intensity, anxiety level. The current study compared the control group that underwent the routine hospital care and pathway group, which followed a preset pathway checklist 
Several observations can be
undertaken from our results. The results
of the present study demonstrate that there
were no statistical significant differences
in the basic data upon admission between
the CPG and control group which included
,age, Sex, level of education, occupation,
associated diseases, prescribes medication,
BMI. These findings roll out the
extraneous factors that might have effect
on VHRS clinical pathway. Additionally,
after completion of data collection
Demographic characteristics of the
studied sample:
The results of the present study demonstrate that there were no statistical significant differences in the basic data upon admission between the CPG and control group which included ,age, Sex, level of education, occupation, associated diseases, prescribes medication, BMI. These findings roll out the extraneous factors that might have effect on VHRS clinical pathway. Additionally, after completion of data collection the statistical tests revealed the significant difference between the CPG and control group patients in relation to basic data 'on admission. As regards to age ; The ageing population has accelerated the contribution of vulvular heart disease to total disease burden. It is predicted that the global aging population will maintain vulvular heart disease as a predominant cause of death worldwide. The WHO reports that the major cause of death of people over 60 years is vulvular heart disease, and vulvular heart disease risk increases as age increases. In many developed countries, the number and proportion of older people (i.e. over 60 years) is increasing(11). Results of the present study is congruent with that where, more than half of both CPG and control group patients were in the age between (51-60 years) with Mean age of both CPG and control groups were approximately equal .(Table 1) . This may indicate that Egypt, like many developing countries, has experienced more rapid urbanization, socioeconomic and health changes, together with an increase in life expectancy.

On the other hands, This result may be far away from results of (12) Where Mean age of vulvular heart replacement surgery cases was 58 years and the metaanalysis of Abdelaal et al (13) who found the mean age of vulvular heart replacement surgery (VHRS) patients was 62 years. This may be owed to the inclusion criteria for the present study of only adults up to 60 years. However one third of the subjects of both the CPG and control group patients were in the age group between 35 to 50 years, this is consistent with other studies which reported that vulvular heart disease mortality in young adults has now been reported in England, the US, France, Australia, and New Zealand(14).

This results may be due to changes in lifestyle factors in the young age including dramatic increasing of obesity, sedentary lifestyles, increasing diabetes, hypertension and persistent smoking in young adults is present study .Regarding sex, more than half of both the CPG and control group patients were males (Table 1). This result is constant with Beltrame et al (15). who said that VHD is the leading cause of mortality for both males and females alike worldwide. Despite the facts that initial manifestation of VHDis delayed in women's by about ten years compared to men's, there is no abrupt that VHD increase the females mortality rates immediately following menopause however a progressive increase over subsequent years. Likewise, Abdelaal etal (13) .Mete-analysis indicates that $60 \%$ of vulvular heart replacement surgery cases were men

As regards the education and occupation are associated with VHD risk factors. In the present study, university Education certificate were held by half of 
'both groups $\mathrm{CP}$ and control group and about half of both patients were occupying a professional work (Table 1). This result may ascertain that increasing educational level and occupying a professional works limit the time for traditional cooking and organized the foods which might be often high in salt, sugar, saturated and trans-fat. Take the calories from sugar and fats has emerge as cheaper and greater reachable than fruit, greens, and vegetables that in turn increase the rates of diabetes mellitus, hypertension and hyperlipidemia .Besides, discourage physical activity, restricted time rise rates of delivery by car instead of shipping through foot, and discourage physical exercises. Moreover, the stress during work and increased rate of smoking increase the risk of VHD.

The present study showed that clinical path group was experienced less pain compared to control group. The difference was statistically significant A statistical significant differences was found between two groups in relation to pain level $(\mathrm{P}=0.000)$.This may be attributed to change the position of $\mathrm{CPG}$ patients after sheath removal and decrease the duration of bed rest in supine position from 12 hours to 8 hours. Moreover pursed lip breathing exercise might play an important role in decreasing pain after surgery . This proves how a very simple and cost free nursing intervention can effectively improve the patients outcome after cardiac valve surgery

The findings in the present study are in line with Fowlow et al. (16) who stated that ambulation of patients as early as possible after connected tubes removal appears to be associated with a reduction in pain perception. Bed rest for long time after VHRS in the supine position is difficult for many patients, who complain frequently of back pain and a desire to move from side to side to relieve the pain. Also the results are in accordance with Koch et al. (17) who reported that reduction bed rest less than six hours time period after diagnostic and interventional coronary procedures add to the patients comfort. Moreover ,Rezaei - Adaryani et al. (18) claimed that changing patients position in bed and the reduced duration of bed rest after cardiac catheterization may also lead to higher levels of comfort and decrease the pain .

As for anxiety it was observed that the CPG had significantly lower level of anxiety than the control group both before and after surgery. This may be related to Information given to $\mathrm{CPG}$ patients before operation compared to with control group patients. Additionally, after surgery significant decrease in back pain sensation in CPG patients than control group ones may play an important role in anxiety levels reduction Furthermore, discharge instructions and booklet handout given patients before discharge may decrease they their worry about what to expect and what, do after discharge.

The present study finding was in agreement with Santamaria and others

(19) who reported that mean anxiety levels were significantly decreased in chronic obstructive pulmonary disease pathway patients than the standard care group. Furthermore, El - Baz (20) found that patients in the conventional care plan for coronary artery bypass graft (CABG) surgery experienced increase in anxiety level relatively more when compared with the pathway group patients while there was no significant difference between groups in relation to depression levels. Additionally, Rashad (21) described the decrease in anxiety level significantly for patients follow clinical pathway during percutaneous nephrolithotomy.

Moreover, Abdel-Rasol (22) reported significant decrease in anxiety level for patients after $\mathrm{CABG}$ who subjected to a protocol of care of positioning and decrease bed rest duration. Likewise, Turley et al (23) indicate that the 
implementation of a clinical pathway has a positive effect on decreasing patient anxiety levels on patients with breast surgery

Finally the present study is bridging the gap between clinical practice and research in order to translate research findings and apply best evidence into practice. The rising number of vulvular heart replacement surgeries' performed and advances in pharmaceuticals and technology mean that nurses can use VHRS clinical pathway to ensure a consistent approach to the care of patients undergoing vulvular heart replacement surgery in their facility.

\section{Conclusion and Recommendation}

- Clinical pathway implementation has positive effect on postoperative pain where the $\mathrm{CP}$ group experienced less pain than the control group.

- Clinical pathway lower level of anxiety among the $\mathrm{CP}$ group compared to the control group.

\section{References:}

1. Minino A,Murphy S,Xu J,Kochanek. Death ;Final data for 2008.National Vital Statistics Reports Hyattsville :National |Center for Health Statistics ,2011.Vol,59(10).

2. World Health Organization (2016): epidemiology of cardiac surgery .Available at: http://www.who.int/mediacentre/factsh eets/fs 164/en.Accessed on2/4/2016

3. Campbell H, Hotchkiss R, Bradshaw $\mathbf{N}$, Porteous $\mathbf{M}$. Integrated Care Pathways. Br Med J 2012; 316: 133-7. 4.Goodyear HM, Lloyd BW. Quality improvement report: can admission notes be improved by using preprinted assessment sheets?. Quality in Health Care 2013;4: 190-3.

5. Statistical Record of the Open-Heart Unit of National Heart Institute. The reports of 2014.
6. Simo M,Albasini J .Major Ambulatory Surgery and Clinical Pathways :Astimulating Combination.Cirugia Espanola .2013,vol.88(4),pp.228-31.

7. Finkelmeier BA. Cardiothoracic Surgical Nursing. $2^{\text {nd }}$ ed. Philadelphia, Lippincott, 2015; 255-75.

8. Nashef $S$, Roques $F$, Michel $P$, Gauducheau E, Lemeshow $S$, Salamon R. European System for Cardiac Operative Risk Evaluation (EUROscore). European $\mathrm{J}$ of Cardiothoracic Surgery 1999; 16: 9-13.

9. Panella M, Marchisio S, Stanislao F. Reducing clinical variations with clinical pathways: do pathways work? Int J Qual Health Care 2003; 15 (6): 509-21.

10. Hegazy T, Menesi W. Critical Path Segments Scheduling Technique. J. Constr. Engrg. \& Mgmt. 2009; 136(10): 1078-85.

11. Evans-Lacko S, Jarrett M, McCrone P, Thornicroft G. Facilitators and barriers to implementing clinical care pathways. BMC Health Serv Res. 2010; 10: 182-7

12. William J , Siegert RJ, Wong A , McNaughton HK, Effectiveness of a Clinical Pathway for Acute Stroke Care in a District General Hospital: an Audit. BMC Health Services Research 2006, 6: 16-22.

13. Abdelaal E,Rao S, Gilchrist I,Bernat I,Shroff A ,Caputo R,Costerousse O ,Pancholy S ,Bertrand O. Same -day Discharge Compared with Overnight Hospitalization After Uncomplicated Percutenous Coronary Intervention :A systematic Review and Meta Analysis Jam Coll Cardiol intv.2013,vol.6,pp.99

14. O"flahert M,Bishop J,Redpath A, McLaughlin T ,Murphy D,Chalmers J, Capewell S. Cardiac Vlve Diseases Mortality Among Young Adult in Scotland in Relation to Social 
Inequalities :Time Trend Study .BMJ.2009, vol.339.

15. Beltrame F, Dreyer $\mathbf{R}$ and TavellaEpidemology of Cardiac Valve Diseases , Cardiac Valve Disease Current Concept in Epidemiology, Pathophysiology , Diagnostics and Treatment :Croatia : In Tec ,2012.

16. Fowlow B,Price $P$, Fung $T$. Ambulation After Sheath Removal : A Comparison of 6 and 8 hours of bed rest after sheath removal in patients following a PTCA Procedure. Heart 7 Lung .2013,Vol.24,pp28-37.

17. Koch $K$,Piek J,de Winter R ,Mulder K, Schotborgh C ,Tijssen J, Lie I. Two Hours Ambulation After Coronary Angioplasty and Stenting with 6Fr Giding Catheters and Low Dose Heparin .Heart .2011, vol $.80, p p .53-56$.

18. Razaei -Adaryani M,Ahmedi F ,Jafarabadi $\mathbf{M}$. The Effect of Changing Position and Early Ambulation After Cardiac Surgery on Patients Outcomes : A single-blind Randmized Controlled Trial .International Journal of Nursing Studies.2009,vol .46(8),pp.1047-1053.

19. Santamaria N, Conners A,Osteraas J ,Ham J,Boodram B. A prospective Cohort Study of the Efftectiveness of Cliniucal Pathway for Inpatients Management of Acute Exacerbation of Chronic Obstructive Pulmonary Diseases (COPD) .Collegan .2004,vol ,11(1),p.12.
20. El-Baz N.Effect of Clinical Pathway Implementation and Patients Characteristics on Outcomes of Coronary Artery Bypass Graft Surgery .Netherlands :Published DSN dissertations -University of Groningen ,2013

21. Rashad E. The Effect of the Application of Clinical Pathways on Postoperative Outcomes Patients Undergoing Percutenous Nephrolothptomy .Alexandria :Unpublished DSN Dissertation , Faculty of Nursing ,Alexandria University ,2011

22. Abdel-Rasol Z. Effect of NursingIntervention on Condition of Patients Undergoing Coronary Artery Bypass Graft .Alexandira :UnPublished Master Thesis , Faculty of Nursing Alexandira university,2011.

23. Turley K, Tyndall M, Woo D, Mohr T. Radical Outcome Method: A New Approach to Critical Pathways in Congenital Heart Disease. Circulation. 2011; 92: 245-9 